Mineralogical Journal, Vol. 2, No. 2, pp. $63-77$, June, 1957

\title{
SYNTHESIS, CRYSTAL LATTICES AND SOME ELECTRICAL PROPERTIES OF INDIUM TELLURIDES AND SELENIDES
}

\author{
Suezo Sugaike \\ Matsuda Research Laboratory, \\ Tokyo Shibaura Electric Company
}

\begin{abstract}
The crystals of indium tellurides and selenides, $\operatorname{InTe}_{2} \operatorname{In}_{2} \mathrm{Te}_{3}, \operatorname{InTe} e_{3}$, InSe and In $\mathrm{Se}_{3}$, have been synthesized by the double-furnace technique and their crystal lattices have been characterized by X-ray single crystal examinations.

From the results of their electrical conductivity measurements it has been found that all of them are semiconductors, $\mathrm{In}_{2} \mathrm{Te}_{3}$ and InSe being poorly conductive with some ionic character, InTe, In $\mathrm{Te}_{3}$ and $\mathrm{In}_{2} \mathrm{Se}_{3}$ having rather higher conductivities of order of $1 \sim 1 \times 10^{2}(\Omega \mathrm{cm})^{-1}$ at room temperature, and that $\mathrm{In}_{2} \mathrm{Se}_{3}$ shows a peculiar phase transition at $200^{\circ} \mathrm{C}$. The lattice symmetries of these compounds have been compared with those of other III b metal chalcogenides.
\end{abstract}

\section{Introduction}

The chalcogenides of the III b metals in the periodic table have first been studied by W. Klemm and H.U. von Voge18) in 1934. Although the majority of the compounds have been investigated crystallographically by $\mathrm{H}$. Hahn ${ }^{2)-5}$ 'and by $\mathrm{S}$. Schubert ${ }^{16)}$, the data on $\mathrm{InTe}_{3}$ and InSe are missing yet.

From the crystal-chemical view-point it will be interesting to see the similarity as well as difference of the properties of $\mathrm{In}_{2} \mathrm{Se}_{3}$ and $\operatorname{In}_{2} \mathrm{Te}_{3}$. The electronegativity differences $\Delta x$ of indium decrease gradually from 1.2 against sulphur, to 1.1 against selenium and 0.8 against tellurium. These small values of $\Delta x$ suggest, according to Pauling's theory ${ }^{14)}$, their indium compounds to be valence crystals or semiconductors, with the smallness of $\Delta x$ indicating the maximum amount (to the extent of $20 \%$ ) of ionic character of the bonds.

In order to see the bonding character of these compounds, in ad- 
dition to the X-ray single crystal examinations, their electrical conductivities were measured as usual using single crystals.

\section{Synthesis}

There are two methods for preparation of indium selenides and tellurides: In the "wet" method, InSe, for example, is obtained by applying hydrogen selenide $\left(\mathrm{H}_{2} \mathrm{Se}\right)$ on molten indium metal, and in the "dry" method, on the other hand, the same compound is prepared by direct fusion of the stoichiometric mixture of the component substances corresponding to the chemical formula. We have adopted the latter method because of its ease of obtaining larger single crystals. The double-furnace technique have been applied after W.D. Lawson ${ }^{10)}$.

As the starting materials, we used indium metal from New Metal Co. in England guaranteed $99.99 \%$ purity, and tellurium and selenium metals spectroscopically examined in our laboratory.

The transparent fused quartz crucible (ca. $1 \mathrm{~cm}$. in diameter), the stoichiometric mixture of two components within, was evacuated and then sealed off by oxy-hydrogen flame. Since it was inevitable that small amounts of selenium or tellurium were sublimated from the mixture and condensed immediately above the sealed point, a slight amount of tellurium or selenium in excess to the calculated amount was usually added. Moreover, as the vapour pressure of molten liquid of selenide was so high at the maximum heating temperature that the crucible of $1.0 \mathrm{~mm}$. wall thickness was often damaged, accordingly a double quartz crucible was used. The procedures otherwise were identical with those used in the preparation of $\operatorname{In}_{2} \mathrm{Te}_{3}$ crystals previously reported ${ }^{7}$.

In preparing InTe $\mathrm{T}_{3}$ crystals, as they were not homogeneous phase but peritectic when the melt of the stoichiometric mixture was slowly cooled in the ordinary experimental conditions, tellurium was added in excess to the stoichiometric proportion so that the $\operatorname{In} \mathrm{Te}_{3}$ crystals were primarily crystallized out from the melt leaving the 
residue richer in tellurium. This procedure yielded the aggregate for the most part of coarse $\operatorname{InTe}_{3}$ crystals.

\section{Electrical measurements of the prepared crystals}

Determination of electrical conductivity was made using a D.C. potentiometer. Current was passed through the specimens (ca. $10 \times$ $3 \times 1 \mathrm{~mm}$. in most compounds) from gold electrodes plated on them through the process of evaporation. The conductivity was determined by measuring the voltage between a pair of platinum probes fixed by compression near both ends of each specimen, and the temperature was measured with a platinum-platinum $13 \%$ rhodium or a cupper-constantan thermocouple. All the measurements in high temperature were carried out in an atmosphere of nitrogen gas or in vacuo to reduce to minimum the irreversible effects caused by the oxidation of specimens.

Usually the electrical properties of a semiconductor are affected to a considerable extent by crystal imperfections caused, for instance, by impurities, however slight they may be. But the research program here reported was mainly limited to inquiring the "intrinsic" properties of compound that is assumed to be semiconductive and those possibly arising from the peculiar crystal structure. Therefore, the values of the energy gap, which should correspond to the breadth of the forbidden band between the empty and the filled valence band, have been estimated from the temperature dependence of the electrical conductivities, applying the following relation:

$$
\sigma=\sigma_{0} \exp (-\Delta E / 2 k T)
$$

where $\sigma$ is the specific electrical conductivity at the absolute temperature $T^{\circ}, k$ the Boltzmann's constant, and $\Delta E$ the activation energy of charge carriers in the intrinsic electric conduction state or the energy gap.

Further, in order to confirm an abrupt conductivity change in $\mathrm{In}_{2} \mathrm{Se}_{3}$ found by the conductivity measurement, the temperature dependence of thermoelectric motive forces were measured by means 
of an experimental procedure after H.K. Henisch and M. Francois ${ }^{6)}$, the temperature difference across the specimen being maintained within $5 \sim 8^{\circ} \mathrm{C}$. .

\section{Researches on individual products}

I. Indium tellurides. There are four known indium tellurides ${ }^{17}$ : $\operatorname{In}_{2} \mathrm{Te}$, InTe, $\operatorname{In}_{2} \mathrm{Te}_{3}$ and $\mathrm{InTe}$, of which $\operatorname{In}_{2} \mathrm{Te}$ being a peritectic compound, was not studied here.

(1) InTe. K. Schubert, E. Dorre and M. Kluge16) have synthesized this telluride by the dry method in vacuum and determined its crystal structure to be of the TISe type with $a_{0}=8.42_{0} \pm 0.005, c_{0}=7.12_{5} \pm 0$. $005 \mathrm{kX}$, and $c_{0} / a_{0}=0.84_{5} \pm 0.005$. We have taken X-ray photographs of the crystals synthesized by us and confirmed their results.

InTe crystal has splendent lustre and cleaves rather perfectly after $\{110\}$ making, when cleaved, a prism elongated parallel to the $c$ axis. Colour and streak are lead-grey.

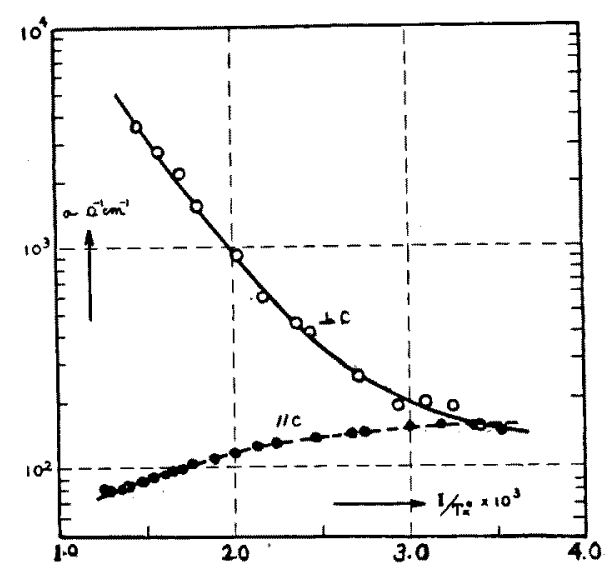

Fig. 1. Temperature dependence of the electrical conductivity of InTe.

Fig. 1 shows the temperature dependence of electrical conductivity of the compound. The abscissa indicates the reciprocal of absolute temperature as in the figures below. The specific conductivity is about $10^{2}$ $(\mathrm{ohm}-\mathrm{cm})^{-1}$ at room temperature. Conductivity as a function of temperature follows different courses according to the crystallographic directions to which current flows; the behavior of conductivity parallel to the $c$ axis is metal-like with a negative temperature coefficient, while perpendicular to it is apparently semiconductive. 
It should be remarked that the thermoelectric motive forces have shown positive sign for both directions measured with the value of $100 \sim 80 \mu \mathrm{V} .1^{\circ} \mathrm{C}$. at near room temperature. At least in that temperature, therefore, the major portions of charge carriers are not electrons but holes in crystal.

More research is necessary to explain the anisotropy of conductivity variance.

(2) $\operatorname{In}_{2}$ Te $_{3}$. H. Hahn and W. Klingler ${ }^{4)}$ prepared $\operatorname{In}_{2} \mathrm{Te}_{3}$ in the form of massive nugget. They found it to be of the sphalerite type in structure with $a_{0}=6.146 \pm 0.005 \AA$. by the X-ray powder method. They concluded that the one-third of equivalent sites for indium were vacant, and were distributed at random. There are $1.33 \mathrm{In}_{2} \mathrm{Te}_{3}$ molecules in the unit cell.

As reported previously?), our X-ray examination of the artificial single crystals revealed the existence of a superlattice with $a_{0}=18.40 \AA$, an about three-fold lattice length. The space group symmetry was determined as $\mathrm{T}_{\mathrm{d}}^{2}-\mathrm{F} \overline{4} \mathrm{~m}$ and with the density of $5.78 \pm 0.04 \mathrm{gr} / \mathrm{cm}^{3}$ at $20^{\circ} \mathrm{C}$, the cell contains $35.6 \pm 0.5$ $\mathrm{In}_{2} \mathrm{Te}_{3}$ molecules. In the crystals crystallized slowly by our pro. cedures, indium atoms are presumably distributed regularly.

$\{111\}$ cleavage surfaces of the crystal have shining metallic lustre. Colour and streak are lead-grey inclining to iron-black.

The results of the electrical conductivity measurement are shown in Fig. 2. In this case temperature dependence is typically of a semiconductor. From the slope of plotted data the

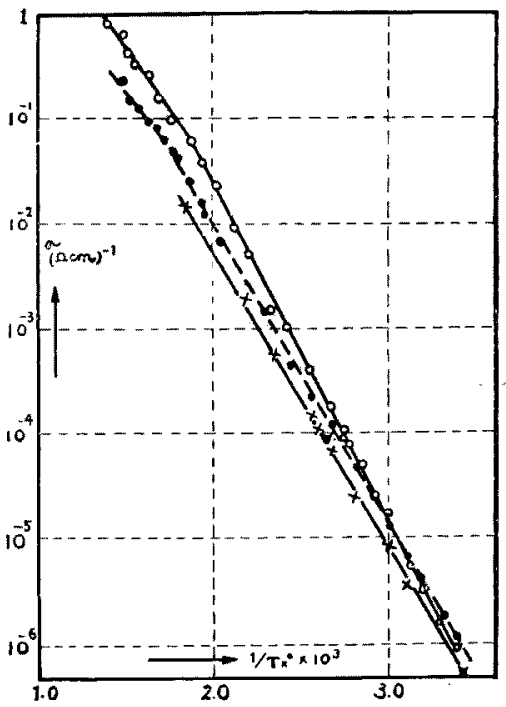

Fig. 2. Temperature dependence of the elestrical conductivity of $\operatorname{In}_{2} \mathrm{Te}_{3}$. 
average values of activation energy $\Delta E$ is calculated to be $1.15 \mathrm{eV}$. between room temperature and $270^{\circ} \mathrm{C}$. and $0.9 \mathrm{eV}$. above $270^{\circ} \mathrm{C}$. . With reference to the conclusion ${ }^{11)}$ deduced from the measurement of photoconductivity, the value $1.15 \mathrm{eV}$. may indicate possibly the energy gap in this telluride. So, so far as our specimens are concerned, at room temperature the crystal is in the intrinsic conduction state as in an ideal ionic crystal, and this may be related to its strong tendency to grow with the exact stoichiometric proportion of constituent elements excluding almost all minor impurities.

Meanwhile, the crystal is piezoelectric.

(3) InTe $e_{3}$. X-ray single crystal oscillation photographs were indexed on the basis of a monoclinic unit cell with $a_{0}=19.7 \AA, b_{0}=4.37 \AA$, $c_{0}=12.8 \AA$. and $\beta=101^{\circ}$. Crystals are occasionally twinned on $\{100\}$, although not observed by the microscopic observation. The possible space group is either $\mathrm{C}_{2 \mathrm{~h}}^{3}-\mathrm{C} 2 / \mathrm{m}, \mathrm{C}_{2}^{3}-\mathrm{C} 2$ or $\mathrm{C}_{\mathrm{s}}^{3}-\mathrm{Cm}$. The unit cell contains $8.04 \mathrm{InTe}_{3}$ molecules calculating from the density of $6.08 \pm 0$.$01 \mathrm{gr} / \mathrm{cm}^{3}$.

The acicular or tabular crystals elongated to the $\mathrm{b}$ axis with perfect $\{100\}$ cleavage can be separated from the ingot prepared by the procedures already explained. Cleavage flakes are very flexible, but not elastic. Lustre is metallic, less splendent on the cleaved surface compared with InTe and $\mathrm{In}_{2} \mathrm{Te}_{3}$ crystals. Streak is grey.

The semiconductive characters of electrical conductivity may be seen in Fig. 3. We note that the $\sigma$ versus $1 / T$ curves (two typical cases

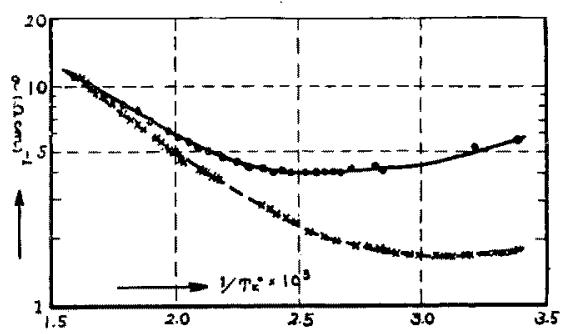

Fig. 3. Temperature dependence of the electrical conductivity of InTe 3 . are shown), although at lower temperature they take different courses according presumably to the difference in contents and sorts of impurities, become a single curve at higher temperature. Extraporating it over the high temperature range not depicted in the figure, we 
have estimated the energy gap to be about $0.5 \mathrm{eV}$.. Recently E. Mooser have obtained by a similar method the value $0.36 \mathrm{eV} .^{*}$ with regard to his $\operatorname{InTe}_{3}$ specimen.

II. Indium selenides. Two of indium selenides, InSe and $\mathrm{In}_{2} \mathrm{Se}_{3}$, were prepared. We know, according to W. Klemm and H.U. von Voge $l^{83}$, the melting points are $660 \pm 10^{\circ} \mathrm{C}$. for InSe and $890 \pm 10^{\circ} \mathrm{C}$. for $\mathrm{In}_{2} \mathrm{Se}_{3}$.

(1) InSe. Recently R.W. Damon and R.W. Redington' 'prepared InSe crystal by the same procedure as described here, and studied the optical and electrical properties.

By the X-ray single crystal oscillation photographs, the hexagonal symmetry was deduced, an orthohexagonal cell having been measured;

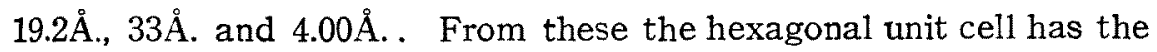
dimensions ; $a_{0}=19.2 \pm 0.1 \AA$., $c_{0}=4.00 \pm 0.02 \AA$. and $c_{0} / a_{0}=0.208$. The $\mathrm{X}$-ray powder diagram was taken by a Norelco spectrometer and indexed (Table 1).

Table 1. X-ray powder data of InSe.

CuKx, 40 KV., $13 \mathrm{~mA}$. (Norelco). Hexagonal; $a_{0}=19.2 \AA ., c_{0}=4.00 \AA$.

\begin{tabular}{|c|c|c|c|c|c|c|c|}
\hline$I$ & $d$ (meas.) & $h k, l$ & $d($ calc. $)$ & $I$ & $d$ (meas.) & $h k, l$ & $d$ (calc.) \\
\hline W & $8.36 \AA$ & 200 & $8.32 \AA$ & $W$ & $1.80 \AA$ & 40,2 & $1.80 \AA$ \\
\hline $\mathrm{s}$ & 4.16 & 40,0 & 4.16 & $\mathrm{VW}$ & 1.73 & 65,0 & 1.74 \\
\hline MSbr & 3.38 & 21,1 & 3.38 & VW & 1.62 & 43,2 & 1.60 \\
\hline VW & 3.14 & 420 & 3.14 & VW & 1.44 & 80,2 & 1.44 \\
\hline Wbr & 3.05 & 22,1 & 3.07 & VW & 1.40 & 102,1 & 1.40 \\
\hline Wbr & 2.96 & 51,0 & 2.99 & $W$ & 1.388 & 120,0 & 1.387 \\
\hline VW & 2.77 & 60,0 & 2.77 & VW & 1.353 & 90,2 & 1.358 \\
\hline Wbr & 2.44 & 44,0 & 2.40 & VW & 1.263 & 104,1 & 1.264 \\
\hline Wbr & 2.38 & 70.0 & 2.38 & VW & 1.197 & 88,0 & 1.201 \\
\hline VW & 2.30 & 60,1 & 2.28 & VW & 1.187 & 140,0 & 1.188 \\
\hline VW & 2.08 & 80,0 & 2.08 & $\mathrm{~W}$ & 1.160 & 123,1 & 1.158 \\
\hline $\mathrm{S}$ & 2.00 & 00,2 & 2.00 & Wbr & 1.154 & 103,2 & 1.153 \\
\hline VW & 1.95 & 71,1 & 1.93 & MSbr & 1.140 & $12 \quad 0,2$ & 1.140 \\
\hline
\end{tabular}

* Private communication from E. Mooser. 
The space group is decided to be $D_{6}^{6}-6_{3} 2$. The density being $5.72 \pm 0.05 \mathrm{~g} / \mathrm{cm}^{3}$ the unit cell contains $22.7 \pm 0.4 \mathrm{InSe}$ molecules. A chemical analysis has given the composition $\operatorname{In}_{1.03} \mathrm{Se}_{1.00}$ for the synthesized crystals.

$\{10 \overline{1} 0\}$ cleavage flakes elongated parallel to the $c$ axis are easily separated from ingot. The crystal is somewhat flexible. Both colour and streak are blackish grey. Although the crystal has dull metallic lustre, a very thin flake is feebly transparent with a dark brownish hue.

Fig. 4 gives typical results of the conductivity measurements on InSe cleavages. The room temperature conductivity parallel to cleav-

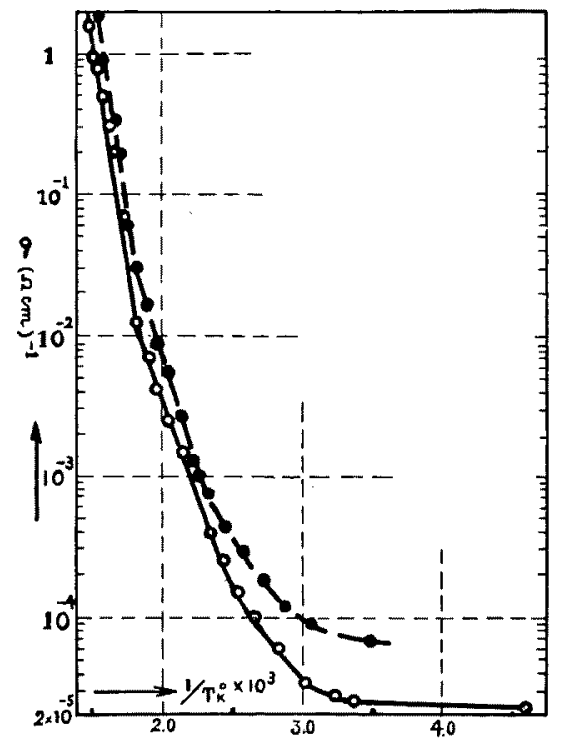

Fig. 4. Temperature dependence of the electrical conductivity of InSe. age plane was measured to be $3 \sim 10 \times 10^{-5}(\mathrm{ohm}-\mathrm{cm})^{-1}$, which is of the same order as that of $\operatorname{In}_{2} \mathrm{Te}_{3}$ crystal. The variation of conductivity at and near room temperature is different, presumably dependent on the amount of impurities in each specimen. At the moderate high and highest temperature ranges, however, the curves become, as in the case of $\operatorname{InTe}_{3}$ described above, straight and parallel to each other. We have noticed that a knick take place on each curve at about $265^{\circ} \mathrm{C}$. . The values $1.15 \mathrm{eV}$. and $2.24 \mathrm{eV}$. were calculated for their activation energies at respective temperature ranges. R.W. Damon and R.W. Redington ${ }^{1 /}$ obtained a somewhat different value for the activation energy $(\Delta E=0.97 \mathrm{eV}$.) for the whole temperature range.

According to H. Miyasawa who experimented with cleaved speci- 
mens supplied by us, a maximum occurs in photoconductivity at the $1.25 \mathrm{eV}$. absorption edge. This has led us to conclude that of the values deduced, $1.15 \mathrm{eV}$. should be taken for the energy gap rather than $2.24 \mathrm{eV}$.. The latter value may have been affected by the ionic conduction which might have taken place within the specimen.

(2) $\operatorname{In}_{2} \mathrm{Se}_{3}$. H. Hahn ${ }^{2}$ reported that $\mathrm{In}_{2} \mathrm{Se}_{3}$ has a hexagonal unit cell with $a_{0}=3.99 \AA$., $c_{\jmath}=19.0 \AA$. and $c_{J} / a_{0}=476$ containing $2 \operatorname{In}_{2} \mathrm{Se}_{3}$ molecules. We have confirmed his result. The $\mathrm{X}$-ray powder diagram (Table 2) taken by a Norelco spectrometer was indexed on the

Table 2. X-ray powder data of $\operatorname{In}_{2} \mathrm{Se}_{3}$.

$\mathrm{Cu} K \alpha, 25 \mathrm{KV}, 18 \mathrm{~mA}$. (Norelco). Hexagonal ; $a_{0}=4.00 \AA ., c_{0}=19.24 \AA$.

\begin{tabular}{lccl|lllll}
\hline \multicolumn{1}{c}{$I$} & $d$ (meas.) & $h k, l$ & $d$ (calc.) & & $I$ & $d$ (meas.) & $h k, l$ & $d$ (calc.) \\
\hline MS & $9.60 \AA$ & 00,2 & $9.62 \AA$ & W & $1.92 \AA$ & 00,10 & $1.92 \AA$ \\
S & 4.82 & 00,4 & 4.81 & VW & 1.86 & 11,4 & 1.85 \\
MS & 3.28 & 10,2 & 3.26 & VW & 1.82 & 10,9 & 1.82 \\
MS & 3.21 & 00,6 & 3.21 & VW & 1.71 & 20,2 & 1.70 \\
W & 3.07 & 10,3 & 3.05 & VW & 1.60 & 00,12 & 1.60 \\
VW & 2.82 & 10,4 & 2.81 & W & 1.37 & 00,14 & 1.37 \\
W & 2.58 & 10,5 & 2.57 & VW & 1.279 & 10,14 & 1.277 \\
W & 2.41 & 00,8 & 2.40 & VW & 1.158 & 30,0 & 1.155 \\
W & 2.37 & 10,6 & 2.35 & W & 1.137 & 30,3 & 1.136 \\
MS & 2.01 & 11,0 & 2.00 & VW & 1.107 & 30,5 & 1.106 \\
VW & 1.99 & 10,8 & 1.98 & & & & \\
\hline
\end{tabular}

basis of the hexagonal unit cell with $a_{0}=4.00 \AA$., $c_{0}=19.24 \AA$. and $c_{0} /$ $a_{0}=4.81$. The space group symmetry was determined to be either $\mathrm{D}_{6 \mathrm{~h}}^{4}-\mathrm{C} 6 / \mathrm{mmc}, \mathrm{C}_{6 \mathrm{v}}^{4}-\mathrm{C} 6 \mathrm{mc}$ or $\mathrm{L}_{3 \mathrm{~h}}^{4}-\mathrm{C} \overline{6} 2 \mathrm{c}$. A chemical analysis showed the composition $\operatorname{In}_{2.00} \mathrm{Se}_{2.95}$ for the synthesized crystals.

The crystal of $\mathrm{In}_{2} \mathrm{Se}_{3}$ is somewhat flexible but not elastic with the very easy cleavage after $\{0001\}$. Colour and streak are blackish grey. Lustre is dull metallic. Generally $\operatorname{In}_{2} \mathrm{Se}_{3}$ and InSe crystals are very similar in appearance, although cleaved surfaces of InSe are rather more resinous. Nevertheless, our studies revealed as will 


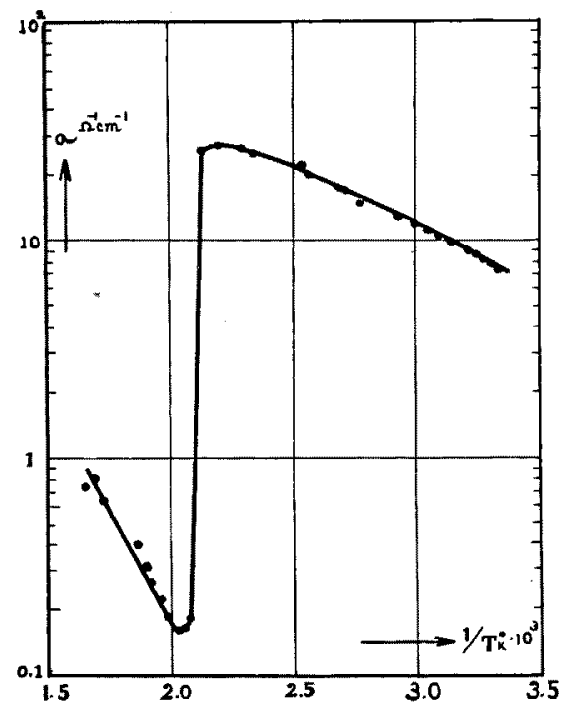

Fig. 5. Temperature dependence of the electrical conductivity of $\mathrm{In}_{2} \mathrm{Se}_{3}$. be described below the remarkable difference in electrical properties between these two compounds.

As seen in Fig. 5, the magnitude of conductivity of $\operatorname{In}_{2} \mathrm{Se}_{3}$ ranges between 10 20 (ohm$\mathrm{cm})^{-1}$ at room temperature. This is large compared with InSe. Moreover, an abrupt change in conductivity taking place at the temperature $200^{\circ} \mathrm{C}$. is observable both by raising and lowering the temperature of measurement, although an appreciable supercooling oc- curs in the latter case.

Corresponding to this a discontinuous change at the same temperature of the thermoelectric motive forces was measured, the temperature measured at the two sides of the specimen slip being averaged (Fig. 6).

These show the existence of a phase transition that occurs at the above mentioned temperature. It is remarked that a differential thermal analysis and a dilatometric measurement ${ }^{12}$, which we have carried out

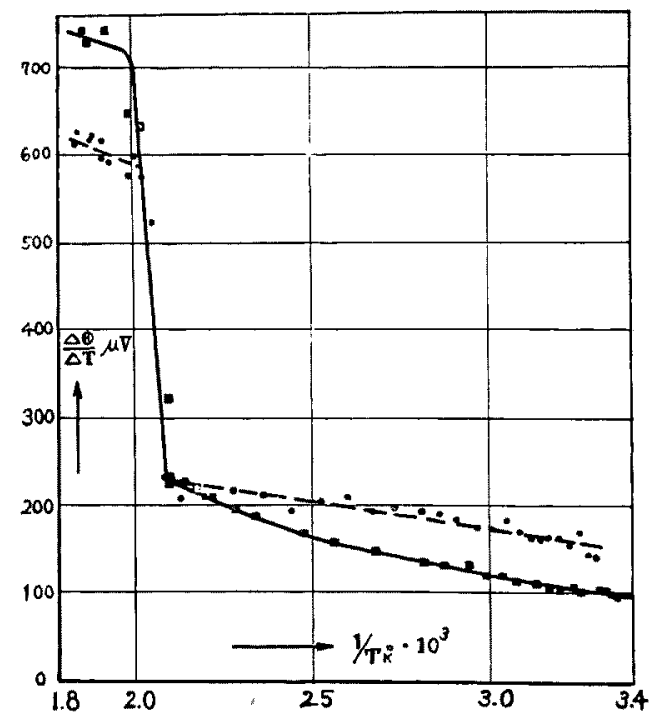

Fig. 6. Relation between thermoelectric motive force $\Delta \Theta / \Delta T$ and average temperature for two typical $\mathrm{In}_{2} \mathrm{Se}_{3}$ specimens. 
on the same specimens have confirmed the result. Details including $\mathrm{X}$-ray data concerning the phase transition will be later reported in another paper.

With the temperature coefficient of conductivity being positive (see Fig. 5), $\operatorname{In}_{2} \mathrm{Se}_{3}$ is, we conclude, no other than a semiconductor in both higher and lower temperature phases. The energy gaps could not be estimated for the above two phases of semiconductor because we were not certain whether we were here dealing with an intrinsic state or not.

\section{Discussion of results}

Indium selenides and tellurides studied here, in spite of their otherwise metallic appearance, have proved to be not metallic but semiconductive substances from their electrical examination. Accordingly it is said that the chemical bond in the compounds is not likely that of metal.

H. Krebs and W. Schottky' pointed out that the covalent bond is necessary to the occurrence of semiconductivity, and compared with a $s p^{3}$ hybridized electron whose eigen function is essentially orientated towards one side of atom, $p$ - or $d$-electron, its eigen-function being orientated towards two or even more directions of space, may easily resonate among those directions resulting to decrease the breadth of energy gap.

E. Mooser and W.B. Pearson ${ }^{13}$ recently concluded from a survey of known various semiconductive compounds including $\operatorname{In}_{2} \mathrm{Te}_{3}$ that semiconductivity is the result of the presence in a solid of predominantly covalent bonds. According to them it is necessary that these bonds through the process of electron sharing, lead to completely filled $s$ and $p$ orbitals in valence shells of at least more electronegative constituent atom, which in most semiconductive compounds lies in IV to VII groups of the periodic table excluding the transition metals of these groups. The presence of empty metallic orbitals in some atoms of a compound, they say, does not destroy semi- 
conductivity provided that these atoms are not bonded together. The covalent bonds must form continuous one-, two- or three-dimensional networks which run through the whole crystal.

So, it may be said, the crystal structure of compounds studied here have the networks of covalent bond from this point of view. In InTe which is isomorphous with TISe, it is found, similarly to the case of TISe interpreted by Mooser and Pearson, that each tellurium atom fills its $s$ and $p$ subshells receiving valence electrons from In atoms, and this situation may be seen by expressing its chemical formula as $\mathrm{In}^{+}\left(\mathrm{In}^{3+} \mathrm{Te}_{2}^{2-}\right)$ from its crystal structure. The crystal consists of the $\mathrm{In}^{3+} \mathrm{Te}_{2}^{2-}$ chains where $\mathrm{In}^{3+}$ is tetrahedrally sur-

Table 3. Lattice types of III b metal mono-chalcogenides.

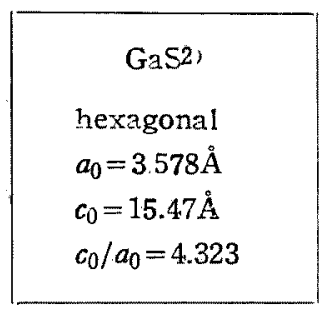

$\operatorname{InS}$

not yet

determined

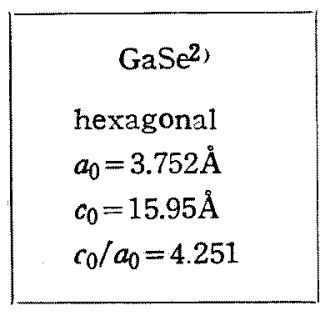

InSe

hexagonal

$a_{0}=19.2 \AA$

$c_{0}=4.00 \AA$

$c_{0} / a_{0}=0.208$
$\mathrm{GaTe}^{2}$ )

monoclinic

$a_{0}=12.76 \AA$

$b_{0}=4.03 \AA$

$c_{0}=14.99 \AA$

$\beta=103.9^{\circ}$

\section{InTel6)}

tetragonal

$a_{0}=8.42 \mathrm{kX}$

$c_{0}=7.12 \mathrm{kX}$

$c_{0} / a_{0}=0.84$

T1Te5)

\section{TlSe ${ }^{5}$}

tetragonal

$a_{0}=8.02 \AA$

$c_{0}=7.00 \AA$

$c_{0} / a_{0}=0.873$ tetragonal

$a_{0}=7.77 \AA$

$c_{J} / a_{0}=0.886$ $c_{0}=6.79 \mathrm{~A}$

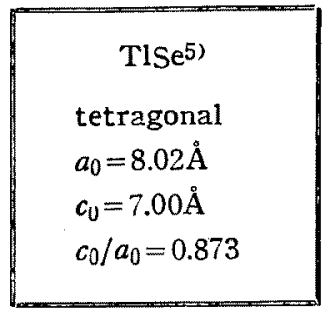

not yet determined, but ascertained to be different from T1Se type.

Compounds in an isomorphous relation are enclosed with same type of black lines. 
rounded by four $\mathrm{Te}^{2-}$ atoms taking $s p^{3}$ hybridized bonds.

In other compounds, although determined here only their unit cell dimensions, such requirement for a semiconductor will be fulfilled in their crystal structures. This may give some clue to possible crystal structur.

Comparing the crystallographic data obtained, InSe and InTe crystals, however, have between them no isomorphous relation. This dissimilarity is also confirmed upon comparing their electrical conductivities with each other. As shown in Table 3 , the monoselenides of III b metals are not isomorphous generally with their corresponding monotellurides. In the chalcogenides of gallium and thallium, it has been reported 25 ) that each of monoselenides has a structural counterpart in monosulphides. This relation can not be ascertained in indium chalcogenides because the crystal data of InS is not known yet. It is thought that the difference between the electronegativities of selenium and tellurium is critical on the properties of chemical bond with which these elements form the $1: 1$ compounds with gallium, indium and thallium.

Although InTe has a tetragonal lattice isomorphous with TISe, InSe appears to have a different lattice from that of GaTe, which has a monoclinic layer lattice as determined by $\mathrm{H}$. $\mathrm{Hahn}^{2}$ and his colleagues.

Moreover, $\mathrm{In}_{2} \mathrm{Se}_{3}$, at least its lower temperature form, is also different from those of $\mathrm{In}_{2} \mathrm{Te}_{3}$ and other chalcogenides of III $\mathrm{b}$ metals as shown in Table 4. A comparison in lattice dimensions with the wurtzite type compounds, $\mathrm{Al}_{2} \mathrm{Se}_{3}, \mathrm{Ga}_{2} \mathrm{~S}_{3}$, etc. might reveal that $\mathrm{In}_{2} \mathrm{Se}_{3}$ has a wurtzite-like superlattice structure. But the intensities of its $\mathrm{X}$-ray powder diagram cannot be fully explained by this simple assumption.

$\mathrm{In}_{2} \mathrm{Se}_{3}$ is also conspicuously differing in its electrical properties from $\mathrm{In}_{2} \mathrm{Te}_{3}$. The former is rather conductive having the remarkable phase transition and the latter, on the other hand, is poorly conductive showing photoconductivity. So it is expected that their 
Table 4. Lattice types of III $b$ metal sesqui-chalcogenides.

\begin{tabular}{|c|c|c|}
\hline $\left.\mathrm{Al}_{2} \mathrm{~S}_{3} 17\right)$ & $\mathrm{Al}_{2} \mathrm{Se}_{3}{ }^{15)}$ & $\mathrm{Al}_{2} \mathrm{Te}_{3}$ \\
\hline $\begin{array}{c}\quad[W] \\
a_{0}=3.70 \AA \\
c_{0}=5.94 \AA \\
c_{0} / a_{0}=1.61\end{array}$ & $\begin{array}{c}\quad[\mathrm{W}] \\
a_{0}=3.890 \AA \\
c_{0}=6.30 \AA \\
c_{0} / a_{0}=1.62\end{array}$ & $\begin{array}{c}\text { not yet } \\
\text { determined }\end{array}$ \\
\hline $\mathrm{Ga}_{2} \mathrm{~S}_{3}{ }^{18}$ & $\left.\mathrm{Ga}_{2} \mathrm{Se}_{3}{ }^{18}\right)$ & $\mathrm{Ga}_{2} \mathrm{Te}_{3}{ }^{18)}$ \\
\hline $\begin{array}{c}\alpha \text { form }[\mathrm{ZnS}] \\
a_{0}=5.181 \AA \\
\beta \text { form } \quad[\mathrm{W}] \\
a_{0}=3.685 \AA \\
c_{0}=6.028 \AA \\
c_{0} / a_{0}=1.636\end{array}$ & $\begin{array}{c}{[\mathrm{ZnS}]} \\
a_{0}=5.429 \AA\end{array}$ & $\begin{array}{c}{[\mathrm{ZnS}]} \\
a_{0}=5.886 \AA\end{array}$ \\
\hline $\operatorname{In}_{2} S_{3}{ }^{18}$ & $\mathrm{In}_{2} \mathrm{Se}_{3}$ & $\mathrm{In}_{2} \mathrm{Te}_{3}$ \\
\hline $\begin{array}{c}\alpha \text { form }\left[\gamma^{\prime} \mathrm{Al}_{2} \mathrm{O}_{3}\right] \\
a_{3}=5.37 \AA \\
\beta \text { form }\left[\gamma \quad \mathrm{Al}_{2} \mathrm{O}_{3}\right] \\
a_{0}=10.74 \AA\end{array}$ & $\begin{array}{l}\text { Hexagonal } \\
a_{0}=4.00 \AA \\
c_{0}=19.24 \AA \\
c_{0} / a_{0}=4.81\end{array}$ & $\begin{array}{c}{[\mathrm{ZnS}]} \\
a_{0}=6.158 \AA \AA^{18)} \\
\text { or } \\
a_{0}=18.40 \AA \\
\text { superlattice type }\end{array}$ \\
\hline
\end{tabular}

[. ] shows the structure type of each compound, and [W] means wurtzite structure.

electronic structures or their characters of covalent bond are much different from each other.

In $\mathrm{In}_{2} \mathrm{Te}_{3}$ with a sphalerite-like structure, valence electrons are in a $s p^{3}$ hybridized state. According to H. Krebs and W. Schottky's discussion, the $s p^{3}$ hybrid bond results larger breadth of the energy gap in semiconductive compounds. This explains the rather insulative property of $\mathrm{In}_{2} \mathrm{Te}_{3}$ having the breadth of energy gap $1.15 \mathrm{eV}$. . On the other hand, because of its much higher conductivity, at least the lower temperature form of $\mathrm{In}_{2} \mathrm{Se}_{3}$ is thought to have a different type of covalent bond from that of $s p^{3}$ hybridization and probably the bond of $p$ electron sharing. From this consideration it may be plausible that the crystal structure of $\operatorname{In}_{2} \mathrm{Se}_{3}$ is not of sphalerite, wurtzite or their superlattice type. 


\section{Acknowledgement}

The author wishes to express his sincere gratitude to prof. $T$. Ito for his interest and guidance, and is indebted to Dr. H. Inuzuka for his kind encouragement throughout this work. The thanks are expressed to Dr. H. Miyasawa for his valuable informations and Messrs. Y. Uemura, J. Okada and M. Takabayashi for their valuable advice on the work.

\section{References}

1) Damon, R.W. \& R.W. Redington: Phys. Rev., 96, 1498 (1954).

2) Hahn, H.: Angew. Chemie, 65, 538 (1953).

3) Hahn, H. \& W. Klingler: Z. anorg. Chem., 259, 135 (1949).

4) Hahn, H. \& W. Klingler: ibid., 260, $\$ 7$ (1949).

5) Hahn, H. \& W. Klingler: ibid., 260, 110 (1949).

6) Henisch. H.K. \& M. Francois: Semiconducting Materials, London, 234 (1951).

7) Inuzuka, H. \& S. Sugaike: Proc. Jap. Acad., 30, 383 (1954).

8) Klemm, W. \& H.U. von Vogel: Z. anorg. u. allgem. Chem., 219, 45 (1934).

9) Krebs, H. \& W. Schottky: Halbleiterprobleme I, (1954).

10) Lawson, W.D.: J. Appl. Phys., 22, 1444 (1951).

11) Miyasawa, H. \& S. Sugaike: J. Phys. Soc. Jap., 9, 648 (1954).

12) Miyasawa, H. \& S. Sugaike: ibid., 12, 312 (1957).

13) Mooser, E. \& W.B. Pearson: Phys. Rev., 101, 1608 (1956).

14) Pauling, L. : The Nature of Chemical Bond, (1939).

15) Schneider, A. \& G. Gattow: Z. anorg. u. allg. Chem., 277, 49 (1954).

16) Schubert, K., E. Dorre \& M. Kluge: Z. Metallkunde, 46, 216 (1955).

17) Smithel's, C.J.: Metals Reference Book, Vol. I, London, 211 (1955).

18) Structure Reports for (1949).

Manuscript received January 10, 1957. 